\title{
Tensor Tympani Muscle
}

National Cancer Institute

\section{Source}

National Cancer Institute. Tensor Tympani Muscle. NCI Thesaurus. Code C33748.

A small, thin muscle of the tympanum located in the middle ear that arises from the pharyngotympanic tube and attaches to the handle of the malleus; it helps to dampen sound vibrations by tensing the tympanic membrane. 